\title{
COSMIC RAYS IN THE HELIOSPHERE
}

Cover illustration adapted from Jokipii and Wibberenz, p. 365: Schematic illustration of the minimum phase of the heliosphere, dominated by the wavy current sheet oscillating about the equator. The radial grey arrows indicate the solar wind and the randomly moving dark lines indicate sample cosmic-ray trajectories. 


\section{Space Sciences Series of ISSI}

Volume 3

The International Space Science Institute is organized as a foundation under Swiss law. It is funded through recurrent contributions from the European Space Agency, the Swiss Confederation, the Swiss National Science Foundation, and the Canton of Bern. For more information, see the homepage at http://ubeclu.unibe.ch/issi/index.html.

The titles in this series are listed at the end of this volume. 


\title{
COSMIC RAYS IN THE HELIOSPHERE \\ Volume Resulting from an ISSI Workshop \\ 17-20 September 1996 and 10-14 March 1997, Bern, Switzerland
}

Edited by

\author{
L. A. FISK \\ Department of Oceanic, Atmospheric, and Space Sciences, \\ University of Michigan, Ann Arbor, MI 48109. USA \\ J. R. JOKIPII \\ Lunar and Planetary Laboratory: \\ University of Arizona, Tucsom, AZ 85721, USA \\ G. M. SIMNETT \\ School of Physics and Astronomy, \\ University of Birmingham, B15 2TT, UK \\ R. VON STEIGER \\ International Space Science Institute, \\ CH-3012 Bern, Switzerland \\ K.-P. WENZEL \\ Space Science Department of ESA, \\ ESTEC, NL-2200 AG Noordwijk. The Netherlands
}

Springer-Science+Business Media, B.V.

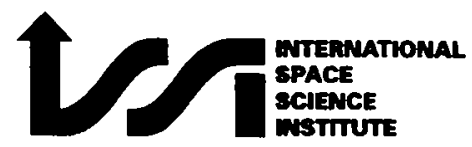

Space Sciences Series of ISSI 
A C.I.P. Catalogue record for this book is available from the Library of Congress.

ISBN 978-90-481-5032-8

ISBN 978-94-017-1189-0 (eBook)

DOI 10.1007/978-94-017-1189-0

Printed on acid-free paper

All Rights Reserved

(C) 1998 Springer Science+Business Media Dordrecht

Originally published by Kluwer Academic Publishers in 1998

No part of the material protected by this copyright notice may be reproduced or utilized in any form or by any means, electronic or mechanical, including photocopying, recording or by any information storage and retrieval system, without written permission from the copyright owner 


\section{TABLE OF CONTENTS}

Foreword $\quad$ xiii

Introduction

L. A. Fisk, J. R. Jokipii, G. M. Simnett, and K.-P. Wenzel 1

\section{INTRODUCTORY PAPERS}

Recurrent Solar Modulation of the Galactic Cosmic Rays and the Anomalous Nuclear Component in Three Dimensions of the Heliosphere

J. A. Simpson

Three-Dimensional Solar Modulation of Cosmic Rays and Anomalous Components in the Inner Heliosphere

R. B. McKibben

Cosmic-Ray Modulation in the Heliosphere - A Phenomenological Study

F. B. McDonald

Anomalous Cosmic Rays and Solar Modulation

A. C. Cummings and E. C. Stone

Cosmic Ray Electrons

P. Evenson

The Solar Wind - Inner Heliosphere

S. T. Suess, J. L. Phillips, D. J. McComas, B. E. Goldstein, M. Neugebauer, and

S. Nerney

Voyager 2 Solar Wind Observations in the Outer Heliosphere

A. J. Lazarus, J. W. Belcher, K. I. Paularena, and J. D. Richardson

Magnetic Fields in the Inner Heliosphere

A. Balogh

Voyager Observations of the Magnetic Field in the Distant Heliosphere

L. F. Burlaga and N. F. Ness

The Theory of Anomalous Cosmic Rays

J. R. Jokipii and J. Giacalone

Modeling of 3-D Corotating Cosmic-Ray Structures in the Heliosphere

J. Kóta and J. R. Jokipii

The Modulation of Galactic Cosmic Rays in the Heliosphere: Theory and Models

M. S. Potgieter

The Inner Heliosphere - Outer Heliosphere Comparison for Cosmic Ray

Modulation

W. R. Webber and J. A. Lockwood 
A Brief History of Recurrent Solar Modulation of the Galactic Cosmic Rays (1937-1990)

J. A. Simpson

\section{WORKING GROUP REPORTS}

Global Processes that Determine Cosmic Ray Modulation - Report of Working Group 1

L. A. Fisk, K.-P. Wenzel, A. Balogh, R. A. Burger, A. C. Cummings, P. Evenson,

B. Heber, J. R. Jokipii, M. B. Krainev, J. Kóta, H. Kunow, J. A. le Roux,

F. B. McDonald, R. B. McKibben, M. S. Potgieter, J. A. Simpson,

C. D. Steenberg, S. Suess, W. R. Webber, G. Wibberenz, M. Zhang, P. Ferrando,

Z. Fujii, J. A. Lockwood, H. Moraal, and E. C. Stone

1. Introduction;

2. Study of the Radial Intensity Gradients of Galactic Cosmic Rays; F. B. McDonald and Z. Fujii

3. Latitudinal Structure of Modulation in the Inner Heliosphere; R. B. McKibben, R. A. Burger, B. Heber, J. R. Jokipii, F. B. McDonald and M. S. Potgieter

4. Anomalous Cosmic Rays and the 22 Year Solar Modulation Cycle; W. R. Webber, J. R. Jokipii, J. Kóta, J. A. Lockwood, C. D. Steenberg,

H. Moraal, M. S. Potgieter, J. A. le Roux, F. B. McDonald, A. C. Cummings and E. C. Stone

5. Charge Dependent Spatial Modulation of Cosmic Rays; B. Heber, M. S. Potgieter, P. Ferrando, G. Wibberenz, P. Evenson and J. R. Jokipii

6. Implications of 26-Day Variations for the Global Modulation; M. Zhang, J. A. Simpson, H. Kunow, J. R. Jokipii, M. S. Potgieter, R. A. Burger and A. C. Cummings

7. Summary;

Note Added at Press Time: North-South Asymmetry in the Heliosphere;

References;

Corotating Particle Events - Report of Working Group 2

G. M. Simnett, H. Kunow, E. Flückiger, B. Heber, T. Horbury, J. Kóta,

A. Lazarus, E. C. Roelof, J. A. Simpson, M. Zhang, and R. B. Decker

1. Introduction; H. Kunow and G. M. Simnett

2. Differences Between Heliospheric Magnetic Field Models; T. Horbury, J. Kóta and E. C. Roelof

3. 26-Day Modulation of High Rigidity Particles by CIRs; H. Kunow, B. Heber, and J. A. Simpson

4. Organizing Phenomena for the Recurrent Modulation; M. Zhang, J. A. Simpson and J. Kóta

5. Association of Recurrent Cosmic Ray Decreases and Energetic Particle Events with Coronal Hole Boundaries; E. C. Roelof and G. M. Simnett

6. Low Energy Particles; G. M. Simnett and E. C. Roelof 
7. Recurrent Structures in the Outer Heliosphere; R. B. Decker and E. C. Roelof

Anomalous Cosmic Rays - Report of Working Group 3

B. Klecker, R. A. Mewaldt, J. W. Bieber, A. C. Cummings, L. Drury, J. Giacalone, J. R. Jokipii, F. C. Jones, M. B. Krainev, M. A. Lee, J. A. le Roux, R. G. Marsden, F. B. McDonald, R. B. McKibben, C. D. Steenberg, M. G. Baring, D. C. Ellison, L. J. Lanzerotti, R. A. Leske, J .E. Mazur, H. Moraal, M. Oetliker, V. S. Ptuskin, R. S. Selesnick, and K. J. Trattner

1. Introduction; R. A. Mewaldt, B. Klecker, and A. C. Cummings

2. Anomalous Cosmic Ray Data Sets; R. G. Marsden, A. C. Cummings, B. Klecker, L. J. Lanzerotti, J. E. Mazur, R. B. McKibben, R. A. Mewaldt and K. J. Trattner

3. Modulation of the Anomalous and Galactic Components of Cosmic Ray $\mathrm{H}$ and He as described by a Full-Drift Two-Dimensional Acceleration Model;

C. D. Steenberg, H. Moraal and F. B. McDonald

4. The Acceleration of Pick-Up Ions at The Solar Wind Termination Shock: A Non-Linear Monte Carlo Calculation; F. C. Jones, M. G. Baring and D. C. Ellison

5. Injection and Acceleration of Pickup Ions at the Termination Shock;

J. Giacalone and J. R. Jokipii

6. The Self-Consistent Stochastic Pre-Acceleration of Pickup Ions in the Heliosphere: J. A. le Roux and V. S. Ptuskin

7. The Pre-Acceleration of Anomalous Cosmic Rays in the Inner Heliosphere; J. Giacalone and J. R. Jokipii

8. The Ionic Charge Composition of Anomalous Cosmic Rays; B. Klecker,

R. A. Mewaldt, M. Oetliker, R. S. Selesnick, and J. R. Jokipii

9. A Search for Minor Ions in Anomalous Cosmic Rays; B. Klecker,

R. A. Mewaldt, M. Oetliker, and R. A. Leske

10. Summary;

References;

Transient Effects and Disturbed Conditions - Report of Working Group 4

G. Wibberenz, J. A. le Roux, M. S. Potgieter, and J. W. Bieber

1. Transient Effects and Disturbed Conditions: Observations and Simple Models; G. Wibberenz

2. Application of Time-Dependent Drift Models to Long-term Decreases and Recoveries in the Cosmic Ray Intensity Associated with Merged Interaction Regions; J. A. le Roux and M. S. Potgieter

3. Remarks on the Diffusion Tensor in the Heliosphere; J.W. Bieber 
viii

\section{EPILOGUE}

Cosmic-Ray Transport Coefficients

J. Giacalone

Epilogue: Cosmic Rays in the Active Heliosphere

J. R. Jokipii and G. Wibberenz

List of Acronyms

Author Index

List of Participants 
ISSI Workshop

Cosmic Rays in the Heliosphere

17-20 September 1996, and 10-14 March 1997, Bern, Switzerland

Group Photograph

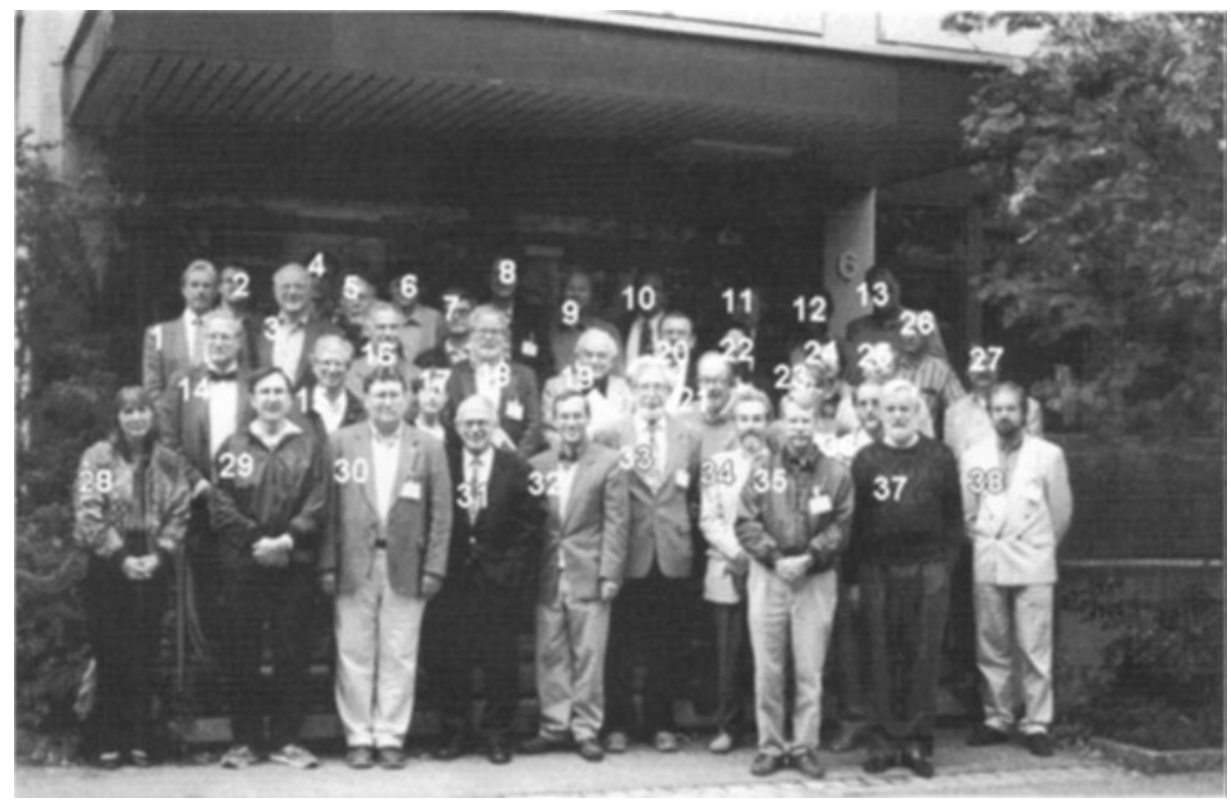

$\begin{array}{rlrlrl}\text { 1. } & \text { G. Simnett } & 14 . & \text { E. Roelof } & 28 . & \text { D. Taylor } \\ \text { 2. } & \text { B. Heber } & 15 . & \text { S. Suess } & 29 . & \text { A. Burger } \\ \text { 3. } & \text { A. Lazarus } & 16 . & \text { A. Balogh } & 30 . & \text { J. Bieber } \\ 4 . & \text { J. le Roux } & 17 . & \text { G. Nusser Jiang } & 31 . & \text { J. Geiss } \\ \text { 5. F. McDonald } & 18 . & \text { R. Mewaldt } & 32 . & \text { P. Wenzel } \\ \text { 6. } & \text { T. Horbury } & 19 . & \text { J. Simpson } & 33 . & \text { G. Wibberenz } \\ \text { 7. } & \text { M. Krainev } & 20 . & \text { R. Jokipii } & 34 . & \text { R. Marsden } \\ \text { 8. } & \text { E. Flückiger } & 21 . & \text { B. Webber } & 35 . & \text { A. Cummings } \\ 9 . & \text { J. Giacalone } & 22 . & \text { M. Hofer } & 36 . & \text { M. Potgieter } \\ \text { 10. } & \text { P. Evenson } & 23 . & \text { B. Klecker } & 37 . & \text { L. Fisk } \\ \text { 11. N. Ness } & 24 . & \text { G. Erdös } & 38 . & \text { L. Drury } \\ \text { 12. } & \text { H. Kunow } & 25 . & \text { B. McKibben } & & \\ \text { 13. } & \text { F. Jones } & 26 . & \text { J. Kóta } & & \\ & & 27 . & \text { M. Lee } & & \end{array}$

Picture by R. von Steiger

Not on this picture: H. Debrunner, C. Steenberg, M. Zhang 


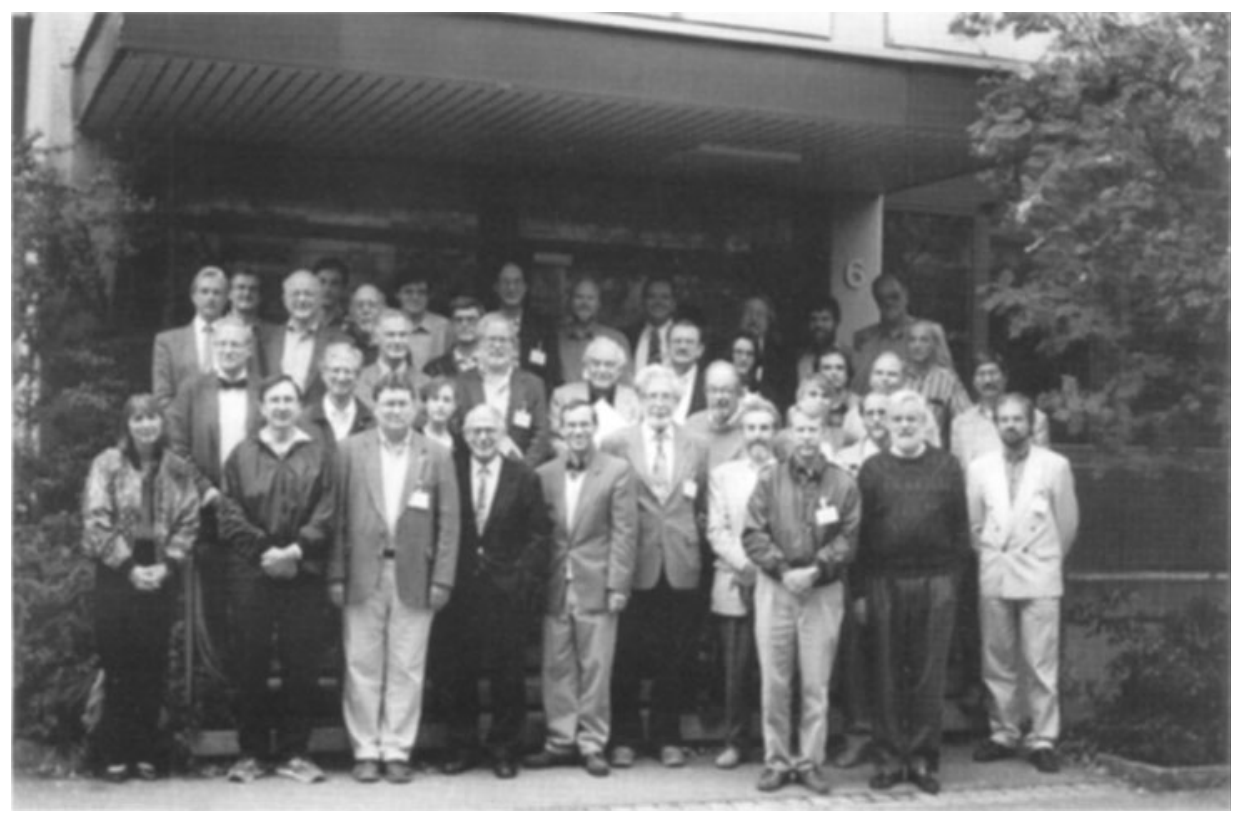




\section{FOREWORD}

In every scientific discipline there are milestones - periods of significant accomplishment when it is appropriate to pause and summarize the state of the field. Such is the case for the study of the behavior of cosmic rays in the heliosphere. We are just passing through solar minimum conditions, when the heliosphere has a well-ordered and relatively simple configuration. We have been fortunate to have an array of spacecraft - unprecedented in the history of space exploration and unlikely to be repeated for generations - to provide comprehensive measurements of cosmic rays throughout the heliosphere. Ulysses has completed its historic first exploration of the heliosphere at high heliographic latitudes. Pioneer and Voyager have been exploring the outer heliosphere. The durable IMP- 8 and now the WIND spacecraft have provided detailed baseline measurements at Earth. Concurrently, there has been a steady improvement in theoretical understanding of cosmic ray behavior through the use of ever more sophisticated numerical models.

This milestone in cosmic ray studies was celebrated with a Workshop on Cosmic Rays in the Heliosphere which was convened by L. A. Fisk, J. R. Jokipii, G. M. Simnett and K.-P. Wenzel at the International Space Science Institute (ISSI) in Bern, Switzerland. The Workshop was attended by 40 scientists from around the world, who have access to cosmic ray and heliospheric data, and knowledge of how cosmic rays should behave. The Workshop met twice, in September, 1996 and March, 1997. This publication is intended to summarize both the discussions and conclusions of the Workshop, and provide a comprehensive overview of the current understanding of Cosmic Rays in the Heliosphere.

The International Space Science Institute (ISSI) was a most suitable forum for this Workshop. ISSI has as its charter the responsibility of assisting the community of space scientists to gather experts in one location and collectively consider the important problems and, from this gathering, to produce a publication which will serve to summarize the state of knowledge and to guide future research. ISSI and its dedicated staff were most considerate and capable hosts of this Workshop, and through their excellent facilitics made possible useful and productive interactions, and a most enjoyable experience.

The editors of this publication are pleased with the result, and hope the community will be as well. The publication, through a series of Introductory Papers, is intended to provide an overview of the state of knowledge of cosmic rays in the heliosphere prior to the Workshop. Four Working Group reports attempt to synthesize this knowledge, make progress in our understanding, and point out directions of future research. These chapters are followed by a summary of the parameters which are used in cosmic ray modulation. Finally, the Workshop, which was concerned primarily with solar minimum, did consider the less well chartered conditions and 
consequences of solar maximum. These speculations are presented in the Epilogue. Each of the chapters was externally reviewed. The extensive efforts of the authors, and the timely cooperation of the reviewers, are greatly appreciated.

November 1997

L. A. Fisk, J. R. Jokipii, G. M. Simnett, R. von Steiger, K.-P. Wenzel 